\title{
Phenotypic and genotypic discrimination of strains of Salmonella serotype Eimsbuettel from human and animal sources
}

\author{
D. C. OLD, PAMELA B. CRICHTON, ANN TAYLOR and SHELLEY C. RANKIN*
}

Department of Medical Microbiology, University of Dundee Medical School, Ninewells Hospital, Dundee DD1 9SY and *Scottish Salmonella Reference Laboratory, Stobhill Hospital, Glasgow G21 3UW

\begin{abstract}
One hundred isolates of Salmonella serotype Eimsbuettel from various human, animal and environmental sources in six countries were typed and shown to belong to five ribotypes, five biotypes and eight different ribotype/biotype groups, one of which, ribotype 3 /biotype 5 , was represented among isolates from all six countries. Most of the Eimsbuettel isolates from Scotland belonged to ribotype 1/biotype 3 , which was the epidemic strain involved in a large outbreak centred in a Glasgow maternity hospital in 1986. That strain was also responsible for almost all the human infections that occurred in the west of Scotland in the years of this study. However, isolates from human cases in the east of Scotland belonged to either ribotype 2 /biotype 1 or ribotype 3 /biotype 5 , groups not found in the west of Scotland. Representatives of all three ribotype/biotype groups causing human infection in Scotland were also found among isolates from poultry or poultry-associated materials. Plasmids were carried by only $14 \%$ of isolates and so provided little additional strain discrimination. However, plasmid analysis suggested that Salmonella Eimsbuettel of ribotype 2/biotype 1 had the potential to enter the human food chain in the UK via meat or bone meal, animal feed and poultry.
\end{abstract}

\section{Introduction}

Salmonella serotype Eimsbuettel (antigenic formula $6,7, \underline{14}: \mathrm{d}: 1, \mathrm{w})$ was first isolated in 1959 from imported North American blood meal at the Veterinary Research Institute in Hamburg and was named after a district in that city [1]. Eimsbuettel is closely related to serotype Livingstone (antigenic formula 6,7:d:1,w) [2], from which it differs only in cell-wall antigen O14, synthesised after lysogeny by bacteriophage $\phi 14$ [3].

In the UK, isolations of serotype Eimsbuettel, like those of Livingstone [4-6], have usually been made from food animals and feed products. Thus, 14 incidents of Eimsbuettel infection reported in statutory animal species in England, Wales and Scotland from 1977 to 1994 involved fowls (nine incidents), pigs (four) and sheep (one) [7, 8]. Isolations of Eimsbuettel from human sources also occur infrequently; e.g., only 22 sporadic human cases of Eimsbuettel infection were recorded in Scotland in 1987-1992 (Mr D. S.

Received 15 Nov. 1996; accepted 13 Dec. 1996

Corresponding author: Dr D. C. Old.
Munro, personal communication) and only nine in England and Wales in 1990-1995 (Dr B. Rowe, personal communication).

Nevertheless, Eimsbuettel and Livingstone, although generally uncommon in the UK, have caused large outbreaks of human infection in Scotland. An outbreak of Eimsbuettel infection in a Glasgow hospital in 1986, involving newborn babies, their mothers and members of staff, was spread by rectal thermometers [9]. Again, serotype Livingstone was the third most common Salmonella isolated from human cases of salmonellosis in Tayside in 1989-1991 [10]. Thereafter, it spread to other regions of Scotland [10,11].

Because Eimsbuettel and Livingstone are isolated so infrequently in the UK, no phage-typing schemes have been developed for primary strain discrimination of these relatively new serotypes. Accordingly, a multiple typing scheme, based on both phenotypic and genotypic properties, was developed successfully for Livingstone strains [12]. The same typing methods were used in this study to identify relationships among strains of Eimsbuettel from diverse sources in Scotland and other countries. 


\section{Materials and methods}

\section{Bacteria}

Details of the sources and donors of 100 isolates of Salmonella Eimsbuettel examined are shown in Table 1. Scottish isolates included: 23 from sporadic human cases or family outbreaks in various parts of the country between 1977 and 1993; 31 from neonates and adults involved in an outbreak at a maternity hospital in Glasgow (in the west of Scotland) in 1986 [9]; one from a rectal thermometer associated with that outbreak [9]; and 12 from animals, mainly poultry, or from the environment. The remaining 33, isolated mainly from animal or animal feed sources between 1972 and 1992, included: 10 from England; 10 from Australia; nine from Canada; three from France and one from Israel.

The isolates were serotyped at the Scottish Salmonella Reference Laboratory (Stobhill Hospital, Glasgow, G21 3UW), and confirmed as Eimsbuettel $(6,7,14$ : $\mathrm{d}: \mathrm{l}, \mathrm{w})$. Cultures were stored on Dorset's egg slopes at ambient temperature $\left(18-20^{\circ} \mathrm{C}\right)$ until they were subcultured on blood agar (Oxoid Columbia Blood Agar Base containing defibrinated horse blood 5\% $\mathrm{v} / \mathrm{v})$ at $37^{\circ} \mathrm{C}$.

\section{Biotyping tests for differentiation of strains of Salmonella Eimsbuettel}

Isolates were examined for their ability to ferment and utilise as sole carbon and energy source a series of 27 carbohydrates (see below); the methods used were the same as those described previously for biotyping Livingstone strains [12]. Isolates were also tested by previously detailed methods [13] for utilisation of $d$ - and $l$-tartaric acids and production of aldehyde from glycerol in Stern's medium.

\section{Ribotyping of Salmonella Eimsbuettel}

The methods for DNA extraction, EcoRI digestion and Southern hybridisation have been reported in detail elsewhere [12].

The gene probe of Escherichia coli ribosomal RNA was the 3.8-kb $P v u$ II restriction fragment of pT711 [12], labelled with digoxygenin by means of the DIG High-Prime system (Boehringer Mannheim). DIGlabelled hybrids were detected with the chemiluminescent substrate lumigen PPD, according to the manufacturer's instructions (Boehringer Mannheim). Filters were incubated at $37^{\circ} \mathrm{C}$ for $15 \mathrm{~min}$ and exposed to Kodak X-OMAT AR film for $\leqslant 1 \mathrm{~h}$ before development. Sizes of hybridised fragments were calculated with reference to those of phage lambda DNA digested with HindIII and EcoRI and labelled with digoxygenin (Boehringer Mannheim).

\section{Plasmid profiling of Salmonella Eimsbuettel}

The method of analysing the plasmid profile, which was performed on at least two occasions for each isolate, has been described previously [14]. Plasmid DNA was examined initially in crude lysates after centrifugation for $15 \mathrm{~min}(c .10 \mathrm{~g})$ in a microfuge. Supernate $(100 \mu 1)$ was loaded on a vertical agarose gel (Sigma type II, $0.7 \% \mathrm{w} / \mathrm{v}$ ) together with $5 \mu \mathrm{l}$ of tracking dye (sucrose $25 \% \mathrm{w} / \mathrm{v}, 8 \mathrm{mM}$ sodium acetate, $3.5 \mathrm{mM}$ SDS and $0.7 \mathrm{~mm}$ bromophenol blue). Electrophoresis was for $1 \mathrm{~h}$ at $100 \mathrm{~V}$ followed by $4 \mathrm{~h}$ at $200 \mathrm{~V}$ (constant voltage). Gels were stained in ethidium bromide $(6 \mu \mathrm{g} / \mathrm{ml}$ for $15 \mathrm{~min})$, viewed by UV light $(365 \mathrm{~nm})$ and photographed on type 665 Polaroid film. The mol.wts of large plasmids $(>10 \mathrm{MDa})$ were determined with reference to plasmids of known mol.wt and those of small plasmids with reference to

Table 1. Country of origin, donor, number and source of 100 isolates of Salmonella Eimsbuettel

\begin{tabular}{|c|c|c|}
\hline Country of origin & Donor & Number and source of isolates \\
\hline \multirow[t]{3}{*}{ Scotland } & $\begin{array}{l}\text { Dr D. C. Old. } \\
\text { Mr D. S. Munro, Scottish Salmonella Reference } \\
\text { Laboratory, Stobhill Hospital, Glasgow }\end{array}$ & $\begin{array}{l}23 \text { Sporadic human cases and family outbreaks in Scotland, } \\
1977-1993\end{array}$ \\
\hline & Mr D. S. Munro & $\begin{array}{l}32 \text { Patients and staff (31) and a thermometer (1) from a } \\
\text { Glasgow hospital outbreak, } 1986\end{array}$ \\
\hline & & 12 Poultry (9), pig (1), environment (2) \\
\hline \multirow[t]{2}{*}{ England } & $\begin{array}{l}\text { Dr C. Wray, Central Veterinary Laboratory, } \\
\text { Weybridge. }\end{array}$ & 8 Poultry feed/poultry waste \\
\hline & $\begin{array}{l}\text { Dr B. Rowe, Laboratory of Enteric Pathogens, } \\
\text { Central Public Health Laboratory, London. }\end{array}$ & 2 Man (1), poultry (1) \\
\hline Australia & $\begin{array}{l}\text { Dr D. Lightfoot, Department of Microbiology, } \\
\text { The University of Melbourne, Parkville, Victoria }\end{array}$ & 10 Bone meal (9), cotton seed meal (1) \\
\hline Canada & $\begin{array}{l}\text { Dr C. Poppe, Agriculture Canada, Health Animals } \\
\text { Laboratory, Guelph, Ontario }\end{array}$ & $\begin{array}{l}9 \text { Meat/bone meal (3), poultry litter (3), animal feed (2), } \\
\text { cat (1) }\end{array}$ \\
\hline France & $\begin{array}{l}\text { Dr M. Y. Popoff, WHO Collaborating Center } \\
\text { for Reference and Research on Salmonella, Unite } \\
\text { des Entérobactéries, Institut Pasteur, Paris. }\end{array}$ & 3 Animal kidney (1), fish (1), poultry (1) \\
\hline Israel & $\begin{array}{l}\text { Dr I. Sechter, Ministry of Health, Government } \\
\text { Central Laboratories, Jerusalem }\end{array}$ & 1 Unspecified \\
\hline
\end{tabular}


supercoiled ladder (Life Technologies) [14]. For restriction fragment analysis, plasmid DNA was extracted after alkaline SDS lysis and purified by phenol-chloroform treatment followed by isopropanol precipitation, ribonuclease treatment and ethanol precipitation [14].

\section{Results}

\section{Biotypes of Salmonella Eimsbuettel}

All of the 100 isolates of Eimsbuettel produced gas from the fermentation of glucose and, when tested by the methods outlined before [12], gave consistent results in fermentation and utilisation tests with the following carbohydrates: all positive for L-arabinose, dulcitol, D-fructose, L-fucose, D-galactose, maltose, Dmannose, L-rhamnose, D-ribose, D-sorbitol, D-trehalose, D-xylose; all negative for adonitol, D-amygdalin, Larabitol, arbutin, D-cellobiose, 2-deoxy-D-galactose, 2deoxy-D-glucose, $o$-methyl- $\alpha$-D-glucose, myo-inositol, D-lyxose, D-melezitose, D-raffinose, L-sorbose, xylitol and L-xylose. These results obtained with Eimsbuettel strains were identical to those previously reported for Livingstone strains [12]; thus, these 27 substrates provided no discrimination among strains of Eimsbuettel.

However, when the 100 isolates were tested for utilisation of $d$-tartaric acid and $l$-tartaric acid and for reduction of glycerol in Stern's medium, 72 utilised $d$-tartaric acid $\left(\mathrm{dt}^{+}\right), 41$ utilised $l$-tartaric acid $\left(1 \mathrm{t}^{+}\right)$and 84 formed aldehyde from glycerol in Stern's medium $\left(\mathrm{Sg}^{+}\right)$. Reproducible results were obtained when cultures were tested on two or more occasions, weeks or months apart. Five of the eight possible biotypes (BTs) recognisable with these three biotyping tests were identified, as follows: BT1 $\left(\mathrm{dt}^{+}, 1 \mathrm{t}^{+}, \mathrm{Sg}^{+}\right)$, 14 isolates; BT3 $\left(\mathrm{dt}^{+}, 1 \mathrm{t}^{-}, \mathrm{Sg}^{+}\right), 58$ isolates; $\mathrm{BT} 5$ $\left(\mathrm{dt}^{-}, 1 \mathrm{t}^{+}, \mathrm{Sg}^{+}\right), 12$ isolates; BT6 $\left(\mathrm{dt}^{-}, 1 \mathrm{t}^{+}, \mathrm{Sg}^{-}\right), 15$ isolates; and BT8 $\left(\mathrm{dt}^{-}, 1 \mathrm{t}^{-}, \mathrm{Sg}^{-}\right), 1$ isolate. Representatives of BTs $2\left(\mathrm{dt}^{+}, 1 \mathrm{t}^{+}, \mathrm{Sg}^{-}\right), 4\left(\mathrm{dt}^{+}, 1 \mathrm{t}^{-}, \mathrm{Sg}^{-}\right)$ and $7\left(\mathrm{dt}^{-}, 1 \mathrm{t}^{-}, \mathrm{Sg}^{+}\right)$were not found. In the Scottish series, BT1 (10 isolates), BT3 (54 isolates, including all 32 associated with the hospital outbreak in Scotland in 1986) and BT5 (three isolates) were represented.

\section{Ribotypes of Salmonella Eimsbuettel}

Of the five different ribotype patterns (ribotypes) detected among Eimsbuettel isolates (Fig. 1), four ribotypes (RTs 1-4) had been previously recognised among Livingstone strains [12]. In this series, 99 isolates of Eimsbuettel were distributed as follows: RT1 (55 isolates), RT2 (17), RT3 (25) and RT4 (2) (Table 2). The remaining isolate belonged to a ribotype, designated RT6 (Fig. 1), which differed from RT1 in its pattern of low-mol.-wt bands. Ribotype 5 (RT5), which was found among strains of Livingstone [12], was not

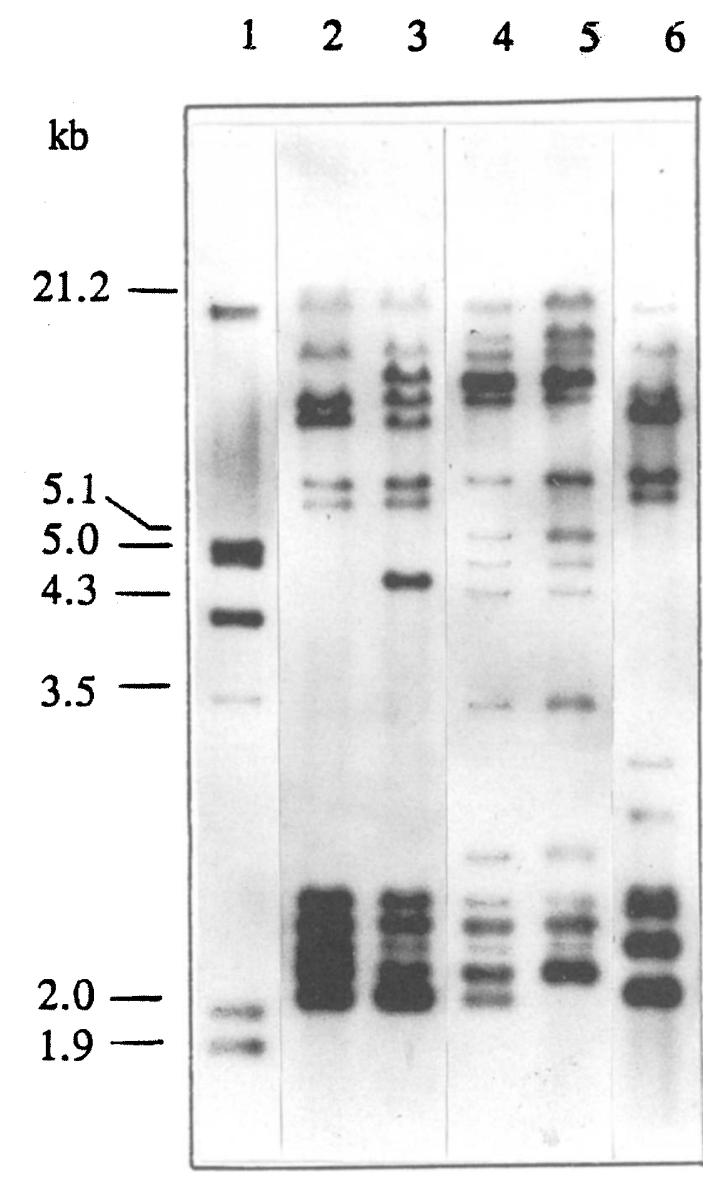

Fig. 1. Ribotype profiles of Salmonella Eimsbuettel strains showing: lane 1, mol.-wt markers; 2-6, ribotypes $1,2,3,4$ and 6 , respectively.

represented among the 100 Eimsbuettel isolates analysed in this study.

The combined use of biotyping and ribotyping provided additional discrimination of serotype Eimsbuettel by identifying two different subgroups within each of the ribotypes RT1, RT2 and RT3 (Table 2). The following ribotype/biotype combinations were observed: RT1/BT3 (54 isolates) and RT1/BT8 (1); RT2/BT1 (14 isolates) and RT2/BT3 (3); and, RT3/BT5 (10 isolates) and RT3/BT6 (15) (Table 2). Each of the ribotypes RT4 and RT6 comprised isolates of only one biotype (Table 2).

\section{Plasmid profiles of Salmonella Eimsbuettel}

Of the 100 isolates examined, 86 were plasmid-free. Among the 14 that carried plasmids, there were 11 different plasmid profiles (Table 2), nine of which were represented by a single isolate. Again, only three of the 54 isolates of the largest ribotype/biotype group (RT1/BT3) carried plasmids: two of these were poultry isolates from 1990 carrying plasmids of 120,25 and $8 \mathrm{~kb}$ with, or without, another plasmid of $80 \mathrm{~kb}$ (Table 2). Restriction fragment analysis showed that the $110-\mathrm{kb}$ plasmid carried by a human isolate of RT2/ BT1 (from 1990) and the $120-\mathrm{kb}$ poultry isolates of 
Table 2. Distribution of plasmids among isolates of Eimsbuettel of different ribotype/biotype (RT/BT) groups

\begin{tabular}{lccc}
\hline & \multicolumn{2}{c}{ Number of isolates } & Plasmid \\
\cline { 2 - 3 } & tested & $\begin{array}{l}\text { with } \\
\text { plasmids }\end{array}$ & $\begin{array}{l}\text { profile } \\
(\mathrm{kb})\end{array}$ \\
\hline RT/BT group & 54 & 1 & 7.5 \\
RT1/BT3 & & 1 & $120: 25: 8$ \\
& 1 & 1 & $120: 80: 25: 8$ \\
RT1/BT8 & 14 & 1 & 5 \\
RT2/BT1 & & 3 & 15 \\
& 3 & 1 & 30 \\
RT2/BT3 & 10 & 2 & 200 \\
RT3/BT5 & 15 & 0 & 9 \\
RT3/BT6 & 2 & 1 & 90 \\
RT4/BT5 & 1 & 1 & 150 \\
RT6/BT3 & 100 & 14 & $\ldots$ \\
All & & 1 & $\ldots$ \\
\hline
\end{tabular}

RT1/BT3 (from 1990/1992) were variants of one another (data not shown). Plasmids of $30 \mathrm{~kb}$ present in isolates of RT2/BT1, from meat/bone meal and animal feed in England in 1986 and Scottish poultry in 1990, were shown to be identical; so too were the $9-\mathrm{kb}$ plasmids in RT3/BT5 isolates from two members of the same family (Table 2 ).

\section{Isolates from man}

Among 54 isolates from human cases in Scotland, four distinct ribotype/biotype groups were found (Table 3 ). Of the 31 isolates from 22 persons associated with the Glasgow hospital outbreak in 1986, 30 belonged to the same ribotype/biotype group, i.e., RT1/BT3, and were plasmid-free; the remaining isolate, obtained at the time of that outbreak, was also of BT3 but belonged to RT6, a ribotype similar to, but distinguishable from, RT1 (Fig. 1).

Of the 23 isolates from sporadic cases and family incidents in Scotland from 1977 to 1993, i.e., before and after the hospital outbreak, 12 that were isolated from patients in the east of Scotland also belonged to the RT1/BT3 group. The remaining 11 isolates from sporadic cases in the east of Scotland belonged to two distinct ribotype/biotype groups: nine that were isolated between 1977 and 1990 belonged to RT2/BT1 and only one of these (from 1990) carried a plasmid $(110 \mathrm{~kb})$; two isolates, from 1992 and 1993, belonged to RT3/BT5 (Table 3). The only other human isolate in this series (England, 1992) belonged to a fifth group (RT4/BT5), which was not detected among Scottish isolates; this strain carried a $90-\mathrm{kb}$ plasmid.

\section{Isolates from non-human sources}

The other 45 isolates in this series came from diverse non-human sources in six countries (Table 1); they belonged to seven distinct ribotype/biotype groups. The isolate from a rectal thermometer implicated as the vehicle of infection in the hospital outbreak was, like the majority (30 of 31) of human isolates involved in that outbreak, plasmid-free and of RT1/BT3; 10 of the Scottish isolates from poultry (7), pig (1) and environmental sources $(2,1986-1992)$ were also of RT1/BT3. The remaining two poultry isolates belonged to RT2/BT1 (a type observed among human isolates in 1990) or RT3/BT5 (a type recovered a few years later from man) (Table 3).

Nine isolates from England, mainly from poultry and poultry-related feed or waste products, belonged to four different ribotype/biotype groups, three of which - RT1/BT3 (one isolate), RT2/BT1 (four isolates) and RT3/BT5 (one isolate) - were also detected among non-human sources in Scotland. Another three isolates that originated from a single poultry hatchery belonged to RT2/BT3 (Table 3).

Most (21) of the 23 isolates of Eimsbuettel from animals or animal feed supplements in Australia, Canada, France and Israel belonged to RT3 and to two distinct biotypes: BT5 (six isolates) and BT6 (15). These biotypes differed only in their reactions in Stern's glycerol medium (positive in BT5 and negative in BT6). RT3/BT5 was, therefore, the only group of which representatives were found among isolates from all six countries (Table 3 ).

Of the remaining two isolates, one, from a cat in Canada, belonged to RT4/BT5, a type that had also been isolated from a human source in England (see above); the other isolate, from poultry in France, belonged to RT1/BT8, the predominant group among isolates of serotype Livingstone in Scotland [12].

Table 3. Ribotype/biotype (RT/BT) groups and sources of 100 isolates of Salmonella Eimsbuettel

\begin{tabular}{|c|c|c|}
\hline $\begin{array}{l}\text { RT/BT group } \\
\text { (and number } \\
\text { of isolates) }\end{array}$ & $\begin{array}{l}\text { Country of } \\
\text { origin }\end{array}$ & $\begin{array}{l}\text { Source (and } \\
\text { number of isolates) }\end{array}$ \\
\hline \multirow[t]{2}{*}{$1 / 3(54)$} & Scotland & $\begin{array}{l}\text { Man (42), poultry ( } 7) \text {, } \\
\text { environment (2), pig (1), } \\
\text { thermometer (1) }\end{array}$ \\
\hline & England & Poultry (1) \\
\hline $1 / 8(1)$ & France & Poultry (1) \\
\hline \multirow{2}{*}{$2 / 1(14)$} & Scotland & Man (9), poultry (1) \\
\hline & England & $\begin{array}{l}\text { Animal feed (2), meat/bone } \\
\text { meal (2) }\end{array}$ \\
\hline $2 / 3(3)$ & England & Hatchery waste (3) \\
\hline \multirow[t]{6}{*}{$3 / 5(10)$} & Scotland & Man (2), poultry (1) \\
\hline & England & Meat/bone meal (1) \\
\hline & Australia & Cotton seed meal (1) \\
\hline & Canada & Poultry litter (2) \\
\hline & France & Animal kidney (1), fish (1) \\
\hline & Israel & Unspecified (1) \\
\hline \multirow[t]{2}{*}{$3 / 6(15)$} & Australia & Bone meal (9) \\
\hline & Canada & $\begin{array}{l}\text { Meat/bone meal ( } 3 \text { ), animal } \\
\text { feed ( } 2 \text { ), poultry litter ( } 1 \text { ) }\end{array}$ \\
\hline \multirow[t]{2}{*}{$4 / 5(2)$} & England & Man (1) \\
\hline & Canada & Cat (1) \\
\hline $6 / 3(1)$ & Scotland & Man (1) \\
\hline
\end{tabular}




\section{Discussion}

It has been recommended that the names of Salmonella serotypes that are phage-convertible variants of extant serotypes should be suppressed [15]. Thus, in the most recent list of Salmonella serotypes in the KauffmannWhite diagnostic scheme, the serotype name Eimsbuettel has been deleted; isolates with the antigenic formula $6,7,14: \mathrm{d}: 1, \mathrm{w}$ are designated as $\mathrm{O}_{1}{ }^{+}$variants of serotype Livingstone which, in turn, is now designated as 6,7,14: d:l,w [15]. However, not all reference laboratories follow that recommendation; for example, both Salmonella Reference Laboratories in the UK (LEP at CPHL, London, and SSRL in Glasgow) continue to identify these two serotypes independently. We have followed their practice in this paper with the name Eimsbuettel being used to identify isolates of antigenic formula $6,7, \underline{14}$ :d:1,w.

A previous study investigated the epidemiology of strains of serotype Livingstone, particularly those from Scottish sources and, by a combination of biotyping, ribotyping and plasmid profiling, showed that an epidemic strain of Livingstone of ribotype 1/biotype 8 and that carried a $6.5-\mathrm{kb}$ plasmid caused the majority of cases of human salmonellosis that occurred in Tayside in 1989-1991 [12]. Isolates of that same type were responsible for sporadic cases in other parts of Scotland, particularly in Grampian region [12]. The presence of Livingstone isolates of identical type in poultry indicated the likely vehicle of human infections in Scotland [12], but the particular risk factors contributing to such a large outbreak in Tayside patients were never established [11]. In addition, the finding that isolates from certain animal feeds in England were identical by all three typing methods suggested that contaminated poultry feed provided the vehicle for entry of Livingstone into the human food chain [12]. Strains of Livingstone of RT1/BT8 from other countries had plasmid profiles different from that of the Scottish epidemic strain [12]. In all, nine other ribotype/biotype combinations were noted among isolates from diverse sources, including man, in other countries [12].

The success of the multiple typing approach with Livingstone strains encouraged its use with strains of the closely related serotype Eimsbuettel which, like Livingstone, has been responsible for sporadic cases and a major outbreak in Scotland over the years 1977-1993. All isolates were typeable by biotyping (five types) and ribotyping (five types) and a total of eight ribotype/biotype groups was distinguished. Among isolates of Eimsbuettel from patients in Scotland, three major ribotype/biotype combinations were identified. The principal one was an epidemic strain of RT1/BT3 which was responsible for all human cases in the west of Scotland over many years, including those in a hospital outbreak. Although the hospital outbreak was associated with incorrect use and disinfection of rectal thermometers, it is possible that the outbreak strain was introduced into the maternity hospital by the index mother whose baby was the first born of the neonates affected [9]. RT1/BT3 was not represented among isolates from sources outwith the UK.

Isolates from patients in the east of Scotland did not belong to RT1/BT3, but to two other types which were present at different periods: RT2/BT1 between 1977 and 1990 and RT3/BT5 during 1992-1993. Isolates from poultry in Scotland also belonged to these same three groups, RT1/BT3, RT2/BT1 and RT3/BT5, implicating it as the likely vehicle of human infections. The existence of three distinct poultry types in Scotland, and their geographical distribution with time, is of considerable epidemiological interest. Strains of RT3/BT5, which were obtained from donors in all six countries, were associated particularly with meat or bone meals. Inadequate rendering of these products is a recognised risk factor in the transmission of salmonellae to animals and man [16].

Plasmid analysis provided further type differentiation in only a few cases. Thus, restriction endonuclease digest analysis showed that the $30-\mathrm{kb}$ plasmids present in isolates of RT2/BT1 from meat and bone meals and from animal feed from England in 1986 and then from Scottish poultry in 1990 were identical (data not shown), indicating possible routes whereby Eimsbuettel had the potential to enter the human food chain. Furthermore, plasmid analysis revealed that nucleotide sequences in 120 -kb plasmids from poultry isolates of RT1/BT3 were also present in a $110-\mathrm{kb}$ plasmid carried by an isolate of RT2/BT1 from man (Table 2). Thus, two distinct lineages of these related plasmids existed or horizontal transfer of plasmids between these two distinct ribotype/biotype lines had occurred.

Unlike Livingstone, which is commonly found in the top 10 list of Salmonella serotypes from poultry in Scotland [17], Eimsbuettel is responsible for few incidents in fowl (only nine fowl incidents were reported in the UK in the 18-year period 1977-1994 $[7,8]$ ) and yet there is little doubt that it is a poultryassociated Salmonella serotype. First, examples of all three ribotype/biotypes associated with human Eimsbuettel infection in Scotland were also present in poultry. Second, a study of the epidemiological relationship between salmonellae isolated from poultry meat and sewage effluents at a long-stay hospital in Scotland showed Eimsbuettel to be the seventh most commonly isolated Salmonella from raw chicken carcases, a position much higher than that of Livingstone [18] which is associated with more human infections than Eimsbuettel. In that study, isolates of Eimsbuettel were isolated coincidentally from both chicken carcases and sewage effluents at 
the hospital, although no patients were known to be infected with either serotype during the time of the study in 1988-1989 [18]. Rectal thermometers were the likeliest vehicle of infection in the Glasgow hospital outbreak, a consideration confirmed by finding that a thermometer isolate was of the same multiple type as the epidemic strain, but the source of that Eimsbuettel strain remains unclear. Although it might have been imported to the hospital by the index patient in the outbreak, a source such as raw chicken carcases within the hospital cannot be discounted.

The likely source of Livingstone strains responsible for human infections in Scotland was poultry, for isolates from both poultry and man were of the same type, RT1/BT8, and carried a $6.5-\mathrm{kb}$ plasmid [12]. Findings from the present study showed that poultry was also the likely source of strains of all three ribotype/biotypes of Eimsbuettel detected among patients in Scotland. In their study of Livingstone strains, Katouli and colleagues [19] used biochemical fingerprinting by the $\mathrm{PhP}$ system [20] to characterise isolates and found that those from man were quite unlike those from animals and animal feedstuffs; accordingly, they suggested that the latter were unlikely sources of human gastroenteritis in Sweden. One possible explanation for that negative correlation may be that their two collections of strains were incompatible. Thus, the 45 strains from animals and feedstuffs were isolated in Sweden during 1987-1992 whereas the 34 epidemiologically unrelated isolates from sporadic cases of human gastroenteritis had been isolated in 1990-1992 in 10 countries worldwide; thus, only 10 of 34 isolates were from human patients in Sweden and 24 came from nine other countries [19]. By contrast, most of the isolates of Livingstone $(68 \%)$ in our previous study [12] and of Eimsbuettel $(67 \%)$ in the present study came from diverse sources in Scotland which may have assisted the epidemiological analysis. Again, it is not clear whether the study of Katouli et al. [19] included isolates of both Livingstone and its $\mathrm{O}^{+} 4^{+}$variant (i.e., Eimsbuettel) which differ in their biochemical activity.

The present problem with regard to the nomenclature of Salmonella serotypes causes confusion and makes comparison of the results of studies in different countries difficult. For example, in the present study, all isolates from Australia were received as Livingstone [21] and yet were $\mathrm{O} 14^{+}$, i.e., they were isolates of Eimsbuettel. It is important, therefore, to resolve the nomenclatural problem to facilitate international comparisons of salmonella-associated diseases. It could, for example, be suggested that names of apparently related serotypes of Salmonella be retained until detailed studies have resolved their genetic relatedness.
We thank Dr D. Lightfoot, Mr D. S. Munro, Dr M. Y. Popoff, Dr C, Poppe, Dr B. Rowe, Dr I. Sechter and Dr C. Wray for the gift of cultures of Salmonella Eimsbuettel and information about them. The assistance of $\mathrm{Mr} \mathrm{H}$. Mather in confirming the serotype of strains is much appreciated.

\section{References}

1. Kelterborn E. Salmonella species. First isolations, names and occurrence. The Hague, Dr W Junk. 1967: 137.

2. Picton WHA, Stirrup W, Price A, Taylor J. A new salmonella type (Salm. livingstone). J Pathol Bacteriol 1953; 66: 310-312.

3. Le Minor L. Conversions antigéniques chez les Salmonella. VII. Acquisition du facteur 14 par les Salmonella du sousgroupe $C_{1}(6,7)$, après lysogénisation par un phage tempéré isolé de cultures du sous-groupe $\mathrm{C}_{4}[6,(7),(14)]$. Ann Inst Pasteur 1965; 109: 505-515.

4. Odongo MO, McLaren IM, Smith JE, Wray C. A biotyping scheme for Salmonella livingstone. Br Vet $J$ 1990; 146: 75-79.

5. Ministry of Agriculture, Fisheries and Food. Animal salmonellosis 1988. Annual summary. Weybridge, Central Veterinary Laboratory. 1989: 1-58.

6. Old DC, McLaren IM, Wray C. A possible association between Salmonella livingstone strains from man and poultry in Scotland. Vet Rec 1995; 137: 544

7. Ministry of Agriculture, Fisheries and Food. Salmonella in animal and poultry production 1992. Weybridge, Central Veterinary Laboratory. 1993: 1-40.

8. Ministry of Agriculture, Fisheries and Food. Salmonella in animal and poultry production 1994. Weybridge, Central Veterinary Laboratory. 1995: 1-82.

9. McAllister TA, Roud JA, Marshall A, Holland BM, Turner TL. Outbreak of Salmonella eimsbuettel in newborn infants spread by rectal thermometers. Lancet 1986; 1: 1262-1264.

10. Old DC, Porter-Boveri M, Munro DS. Recent emergence of Salmonella of serotype Livingstone in and around Dundee. Communicable Diseases (Scotland) Weekly Report 1990; 34: $6-10$.

11. Old DC, Porter-Boveri M, Munro DS. Human infection in Tayside, Scotland due to Salmonella serotype Livingstone. $J$ Med Microbiol 1994; 40: 134-140.

12. Crichton PB, Old DC, Taylor A, Rankin SC. Characterisation of strains of Salmonella serotype Livingstone by multiple typing. $J$ Med Microbiol 1996; 44: 325-331.

13. Duguid JP, Anderson ES, Alfredsson GA, Barker R, Old DC. A new biotyping scheme for Salmonella typhimurium and its phylogenetic significance. J Med Microbiol 1975; 8: 149-166.

14. Platt DJ, Smith I. Gentamicin-resistant Salmonella typhimurium phage type 204c: molecular studies and strain diversity in a putative bovine outbreak. Epidemiol Infect 1991; 107: 213-223.

15. Popoff MY, Le Minor L. Antigenic formulas of the Salmonella serovars, 6th rvn. WHO Collaborating Centre for Reference and Research on Salmonella. Paris, Institut Pasteur. 1992: 1-145.

16. Reilly WJ. Animal husbandry and human health. Rev Med Microbiol 1991; 2: 170-176.

17. Reilly WJ, Forbes GI, Sharp JCM, Oboegbulem SI, Collier PW, Paterson GM. Poultry-borne salmonellosis in Scotland. Epidemiol Infect 1988; 101: 115-122.

18. Reilly WJ, Oboegbulem SI, Munro DS, Forbes GI. The epidemiological relationship between salmonella isolated from poultry meat and sewage effluents at a long-stay hospital. Epidemiol Infect 1991; 106: 1-10.

19. Katouli M, Wollin R, Gunnarsson A, Kühn I, Möllby R. Biochemical phenotypes of Salmonella Livingstone isolated from humans, animals and feedstuffs in Sweden. Acta Vet Scand 1994; 35: 27-36.

20. Möllby R, Kühn I, Katouli M. Computerised biochemical fingerprinting - a new tool for typing of bacteria. Rev Med Microbiol 1993; 4: 231-241.

21. Australian Salmonella Reference Centre. 1995 Annual report. Adelaide, Institute of Medical and Veterinary Science. 1996: $1-104$. 